\title{
TRADITIONAL KNOWLEDGE ON WILD FIBER PROCESSING OF ALLO IN BHEDETAR OF SUNSARI DISTRICT, NEPAL
}

\author{
Rajeev Deokota*, R.B. Chhetri \\ Department of Environmental Science \& Engineering, Kathmandu University. \\ Dhulikhel, Kavre. Post Box No.6250 Kathmandu, NEPAL. \\ Corresponding author: rajeevchettri@ hotmail.com
}

Received 15 December, 2008; Revised 11 January, 2009

\begin{abstract}
In Bhedetar village in the eastern Sunsari district, rai, magar and tamang people, indigenous to the eastern hills of Nepal, have found an ingenious use for the allo plant (Girardiana diversifolia). They have culturally and socially determined uses for the plant as food, fodder and medicine, but they have also been earning their livelihood by making fabric and clothing from this plant. At the local level, they derive allo fibers from the plant to make sacks, bags, coarse clothes, fishnets and namlo (headstraps to carry load) which is sold in the local market or in some cases is bartered for food or other necessary items in some rural communities. On a more macro level, the allo fibers are outsourced to the capital city of Kathmandu where various items made from allo fiber are prepared and exported from Nepal as handlooms and handicrafts.
\end{abstract}

Keywords: Handloom, allo, fibers, Sunsari district, Nepal.

\section{INTRODUCTION}

The indigenous people, comprised of magar, rai, tamang, newar, brahmin, chhetri, etc, inhabiting the eastern village of Bhedetar in Sunsari district, practice some traditional technology of weaving handlooms by utilizing wild fibers as raw material. Fibers are bast fibers generally extracted from the bark of Girardinia diversifolia, Urtica dioica, Cannabis sativa, Boehmeria macrophylla, B. platyphylla, Ficus semicordata etc. But most of the wild bast fibers are extracted from the bark of Girardinia diversifolia, Urtica dioica, Cannabis sativa (Dunsmore, 1993).

Sunsari is one of the districts in the eastern part of Nepal which has a total area of $1257 \mathrm{sq} \mathrm{km}$. It lies between latitude $26^{0} 52^{\prime}-27^{\circ} 52^{\prime} \mathrm{N}$, and $87^{0} 19^{\prime}-87^{\circ} 59^{\prime} \mathrm{E}$ longitude. The district is bordered by the hilly district of Dhankuta in the north, by Morang district in the east, by Bhojpur, Udaypur and Saptari districts in the west and the plains of India towards the south. The average elevation in the region reaches $152 \mathrm{~m}-1420 \mathrm{~m}$. The soil texture varies from sandy to sandy loam impregnated with the boulders. It has rich floral diversity under the influence of monsoonic sub-tropical and temperate climate. The study area, Bhedetar is located on the northern border adjoining the district of Dhankuta, at an altitude of $1420 \mathrm{~m}$. The remarkable features of this region are lush green vegetation, high precipitation and humidity, high wind velocity and lower temperature in comparison to the neighboring low lying areas of the district. The villages are located in remote areas, where transportation system is poor. Agriculture is the main source of income. Therefore, they are economically backward and mostly dependent on nature for their food, shelter and medicine. This plant based technology of fiber extraction, developed by the indigenous communities is to some extent helpful in meeting the basic requirements of the communities as the items prepared from the allo fibers are sold in the local market or as in some cases, bartered for food or other necessary items. However in recent times, the trend of collection and processing of locally 
available allo fibers and their subsequent transfer to Kathmandu where they are transformed into various items made of nettle fiber of export quality, has been gradually increasing and this has been marked as a handy source of income for the ethnic communities involved.

\section{Taxonomy of Girardiana diversifolia}

The natural fiber of allo comes from the bark of giant nettle Girardinia diversifolia and has been extracted for generations in the high mountain region. The allo plant occurs in most of the high mountain regions of Nepal at the altitude of 1200 and $3000 \mathrm{~m}$. It is a short herb about $2-3 \mathrm{~m}$ high, belonging to the family Urticaceae. The leaves are stalked, palmately and deeply divided, dendate and covered with long stinging hairs with hooked protrusions that cause irritation to human skin.. The flowering season is July - September and the flowers are yellowish, clustered in a panicle. They propagate through seeds or root off-shoots (Manandhar, 2002, Fig.1.). The bark fiber peeled off from the stem yields a silky white fiber which is utilized for making thread, ropes or spun into a yarn. (Figs.2. \& 10.)

\section{MATERIALS AND METHODS}

The present study was conducted during 2007. Regular bimonthly visits were made to Bhedetar of Sunsari district. The ethnobotanical informations were gathered through interviews and discussion with indigenous people involved with the processing of allo fibers. The oral interviews have emphasized the techniques of fiber processing, various items prepared from the fiber and selling cost of the final products, etc. The indigenous technique of the fiber processing has been presented.

\section{RESULTS}

Collection of allo shrubs

Though the extraction process followed by the ethnic communities seems a crude and simple process, however it is a painstaking task. In October - November, the men forage the vicinity and harvest the allo shrubs. The shrubs are chosen on the basis of the stout well developed stem from which the bark bearing the fibers are stripped off later.

\section{Extraction of fibers}

After the shrubs are brought down, the men strip them of their bark, with the help of a sickle or in some cases, peeling with bare hands and lay them to dry in the sun for a period of three-four days. It is the turn of womenfolk next, boiling the bark in water containing ash for a duration of around three hours, depending upon the amount of fiber. The ash is known to make the bark soft and easier for the individual separation of fiber.

\section{Retting}

It is known that the retting process is the operation used to degrade, break down into their component elements and remove the substances which hold the fibers together, mainly pectins, hemicelluloses and lignins, as a preliminary condition for obtaining fibers which can be used in the textile industry. Such substances may be dissolved mechanically, microbiologically, chemically or biochemically. Microbiological retting is generally based on the decomposition of pectins by micro-organisms present in the ground and on the plants. In case of the indigenous method, it is principally the former two which is involved to a large extent.

At the industrial level, the stems of fibrous plants for textile use are retted with chemical retting; using significant doses of chemical products (mainly $\mathrm{NaOH}$, caustic soda), with considerable disadvantages regarding the environment, operator safety and compliance with the regulations in force in many countries. Therefore the indigenous knowledge of this process including: a) retting on the ground; which consists of leaving the cut plants lying on the ground, exposed to the weather and fungal microbial flora; 
b) retting in water; which consists of immersing the plants in retting pits with still water or in running water, such as that of a river or a stream, holds much significance.

\section{Separation of fibers}

After this, the bark is stonewashed at a nearby river and shaken vigorously to separate and clean the fibers. The cleaned fibers are then dried in the sun after which it is ready for use. The fiber is then mixed with crushed limestone to make it a little greasy and easier to handle. All this ethnobotany can be hard work. However, the fibers obtained from these known processes may not be sufficiently separated from one another and/or may have characteristics which do not always allow suitable use in the textile industry. The long fibers are then seperated from the shortened ones and the remaining woody material removed by a process termed as hackling before the fiber is ready for being spun.

\section{Spinning and weaving}

Generally, a wooden top or charkha (spinning wheel) is employed for spinning yarn. In some cases, the fiber is rolled around the waist and the free end is clamped between the teeth. One hand quickly rolls the fiber down-through the teeth, which act as a filter-on to the spinner.

The fineness of the yarn largely depends on the quality of the fiber and skill of the spinner. The thread obtained is suitable for making cloth, sacks, bags, head-straps (namlo) (Fig.3.), rope, fishnets etc. The products designed in Kathmandu for export include allo thread knitted into vests, shawls and variety of new products ranging from bags, cushions covers, wallet, and men and ladies clothing with natural dyes. (Figs 4,5,6,7,8,9.)
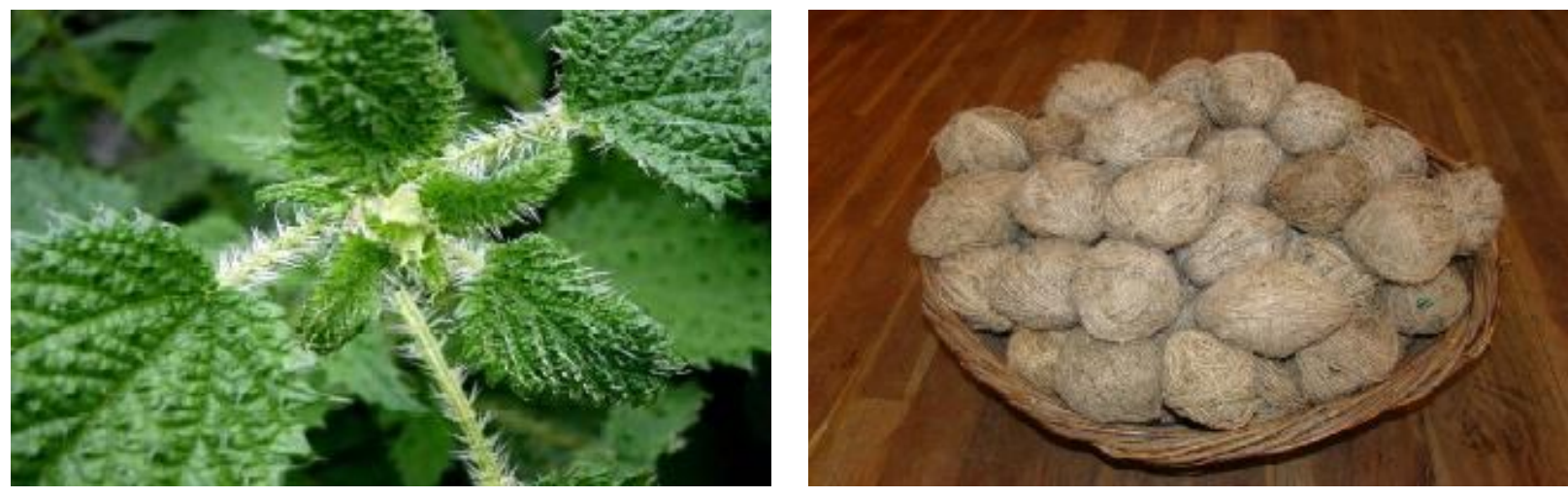

Fig. 1. Allo shrub

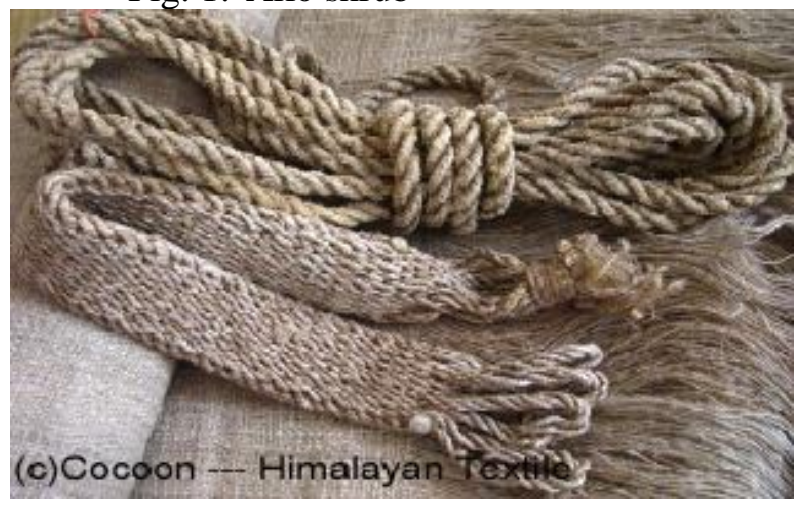

Fig. 3. Head-strap (Namlo)
Fig. 2. Yarn made from allo fiber

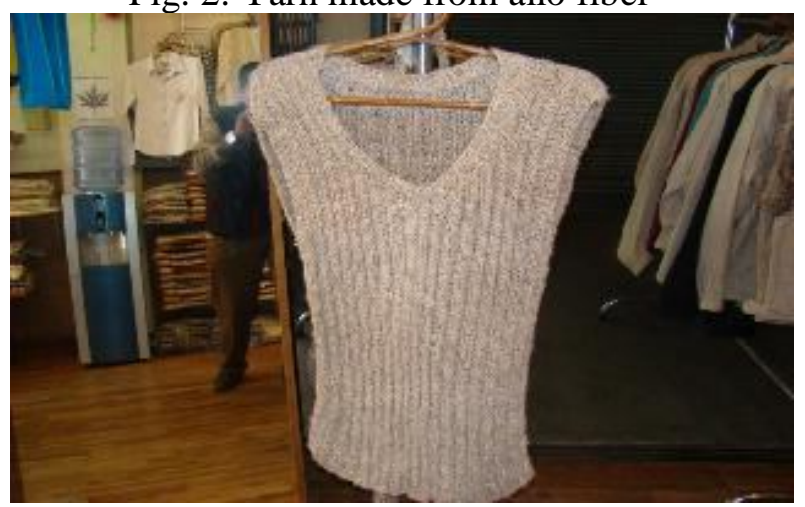

Fig. 4. Vest 
KATHMANDU UNIVERSITY JOURNAL OF SCIENCE, ENGINEERING AND TECHNOLOGY

VOL. 5, No. I, JANUARY, 2009, pp 136- 142.

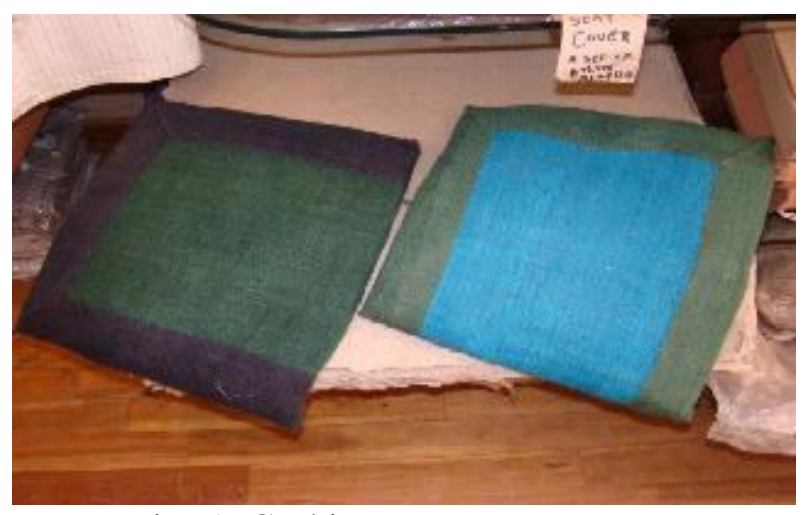

Fig. 5. Cushion covers

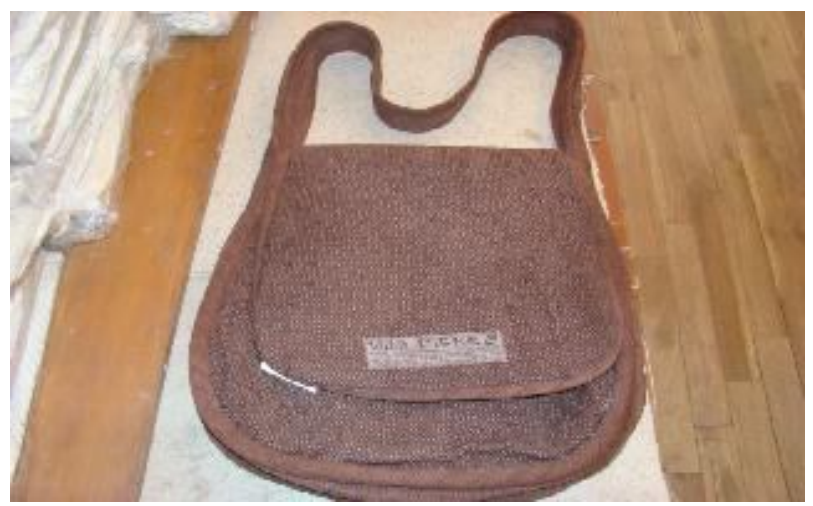

Fig. 7. Satchel

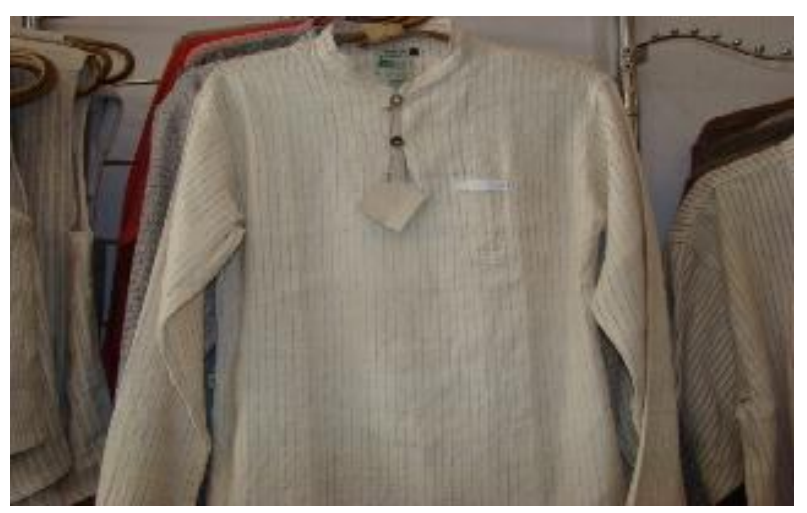

Fig. 9. Shirt

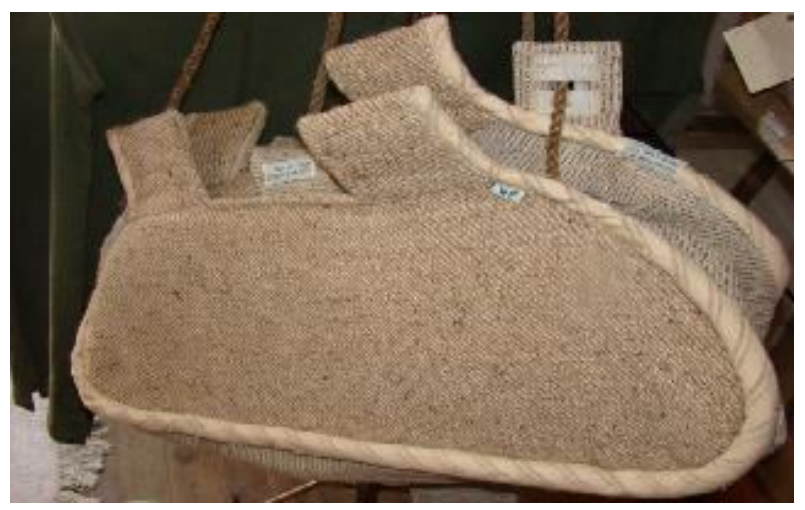

Fig. 6. Ladies handbag



Fig. 8. Ladies handbag

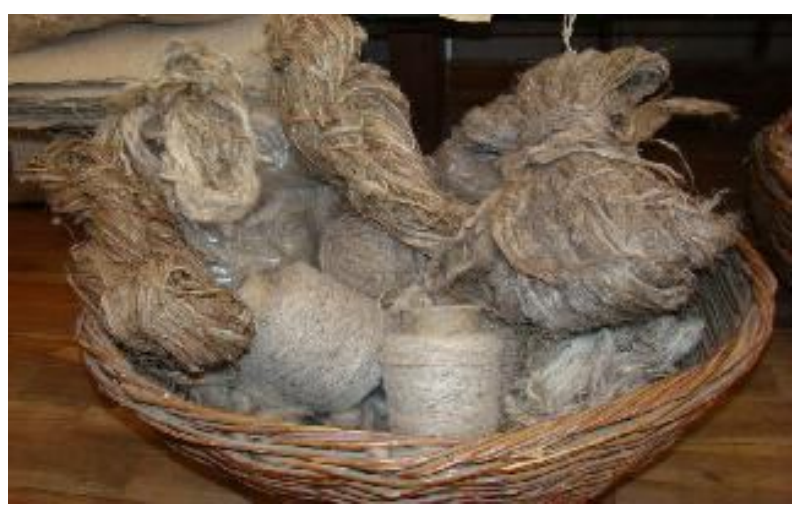

Fig. 10. Yarn spools for weaving 


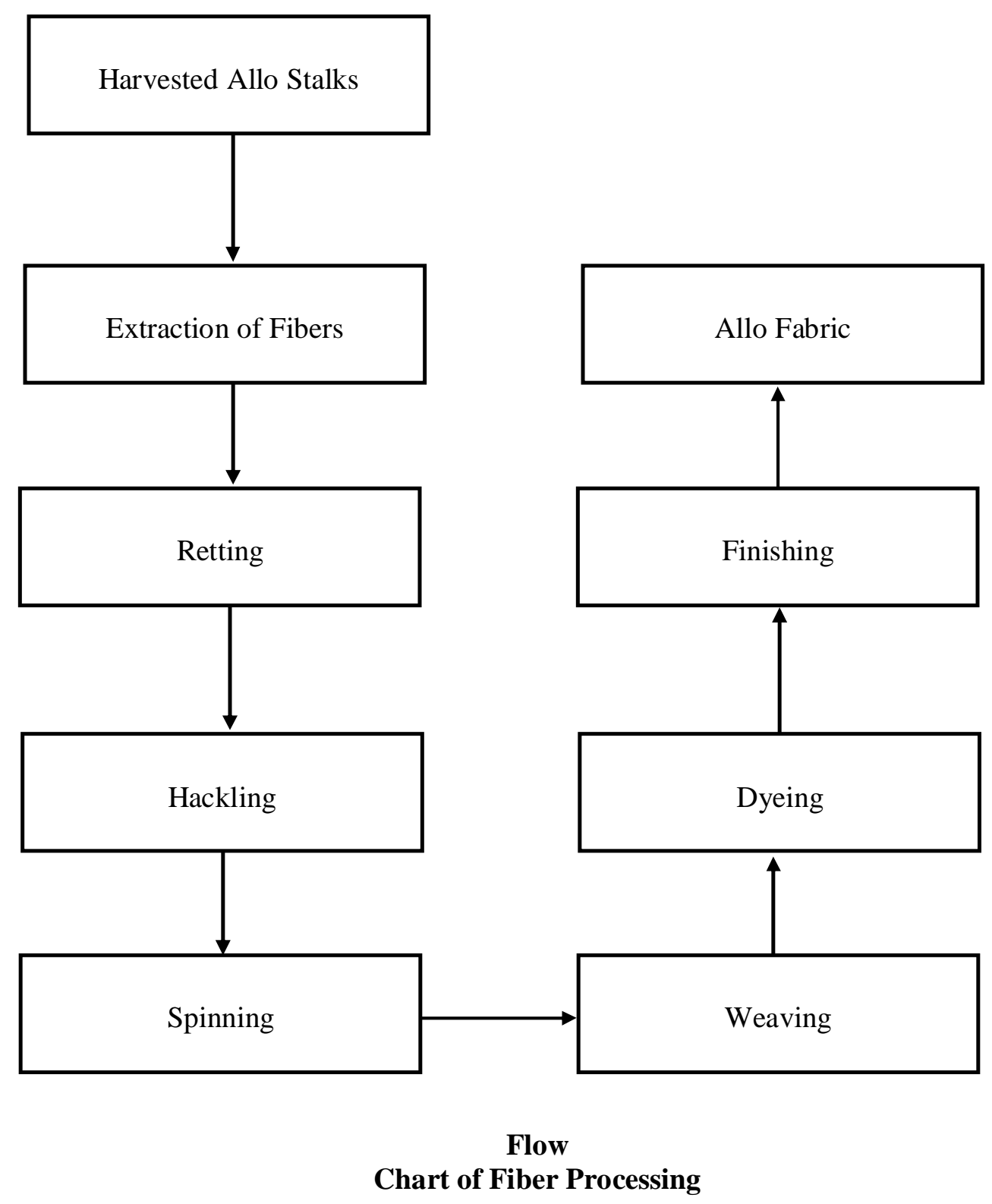

\section{DISCUSSION}

Where do allo fibers fit in and how can it be sustainable in the life of indigenous people? At the end of a life devoted to this painstaking task of traditional extraction of allo fibers, women have wounded and scarred hands and have lost teeth prematurely, and jaws that never seem to stop hurting. But in the recent years, this scenario seems to be gradually changing for the better. Hari Gopal Shrestha, a Bhaktapur-based expert on Nepali textiles, has been working with the Austrian group, Eco Himal, to help the ethnic community Kulung Rai, find better income-generating alternatives (Subedi, 2001). The latest development is heartening. Recently a foot-operated device has been introduced that dispenses 
with the need to use the mouth and works six times as fast as the traditional method, making the process more efficient as well as easy on the workers. Trainings have been conducted for the womenfolk on how to use the new looms (khutte kal) and also new techniques in pattern design. This will surely help the small, but growing market of allo clothing. Eco Himal's initiative to help the Kulung Rai is overseen by the income-generation programme of our community development project. This enhances the possibilities of guaranteeing better market for their products.

Another outlet, located at the heart of Thamel called Wild fibers is exclusively devoted to producing apparels for men and women produced from the fibers of allo, along with other plants of the nettle family and hemp. So, allo handlooms are fast becoming the rage in eclectic circles in Austria and other European countries where it is marketed by Eco Himal. There are however, obstacles to such efforts. Allo has the same rough, husky texture as jute and hemp, and although it is often lighter and more delicate-looking, it is often mistaken for them and not everyone is passionate about coarse fabric (Chodrak \& Tashi,2000). There are ways around this, though, and blending other fabrics with allo, is one solution. There has been experimentation with a variety of different blends which include allo-silk, allocotton, using only natural vegetable dyes in plain colours.

More features are attractive. Allo is cool in the summer and warm in winter, and it's waterproof, durable and can be worn throughout the year. And then there's the gauzy lightweight feel of allo shawls and scarves that makes you feel like you're in a fairy tale world, evoking at every glance the beautiful mountains of eastern Nepal where ingenuity, folk science, and very hard work come together. With reference to the textile industry, fibers can be extracted from natural sources, or they can be synthesized. Natural fibres tend to have an ecological advantage as they are renewable and biodegradable. Synthetic fibres often have a petrochemical origin, and can require significant energy to manufacture (pellets of Nylon 6 take just over $80 \mathrm{MJ} / \mathrm{kg}$ to produce).

Production of fiber from nettles is still insignificant compared to other natural fibers. In the context of Nepal, there are few places that process it commercially, and there is no specially designed equipment. A series of tests to profile the fiber from nettle should be designed to identify how nettle fiber is best used. Mechanical properties are perhaps the most important.

Therefore, it can be envisaged that in the coming days, the scenario of allo derived apparels can become one such sector of sustainable income for the indigenous community who have been practicing this traditional technique from time immemorial.

\section{ACKNOWLEDGEMENT}

The authors are indebted to the indigenous people of Bhedetar of Sunsari district for providing the information on the processing of allo fibers. Thanks are also due to the proprietors and employees of 'Wild fibers', Thamel, Kathmandu for facilitating the study of various items prepared from allo fibers, for sale and export to other countries.

\section{REFERENCES}

1. Chodrak, T \& Tashi, K., 2000. Of Wool and Loom, the Tradition of Tibetan Rugs, White Orchid Books, Bangkok

2. Dunsmore, S., 1993. Nepalese Textile, British Museum Press, 59.

2. Gillow, J \& Sentance, B., 1999 A Visual Guide to Traditional Techniques, (World Textiles) A Bulfinch Press Book. 
4. Manandhar, N.P., 2002. Plants and people of Nepal, Timber Press, Portland, Oregan.

5. Fibranova, G., Tofani. C., \& Errani, M. 2006. Process and system for retting plant fiber for textile use, 2006. World Intellectual Property Organization.

6. Subedi, S., 2001. Say allo, in Nepali Times (issue 48). 